\title{
Studies of sonic booms with seismic networks
}

Bradford Sturtevant and Joseph E. CatesHiroo Kanamori

Citation: 97, 3257 (1995); doi: 10.1121/1.411680

View online: $\mathrm{http}: / / d x . d o i . o r g / 10.1121 / 1.411680$

View Table of Contents: http://asa.scitation.org/toc/jas/97/5

Published by the Acoustical Society of America 
1pPA2. Studies of sonic booms with seismic networks. Bradford Sturtevant, Joseph E. Cates (Graduate Aeronaut. Labs., California Inst. of Technol., Caltech 301-46, Pasadena, CA 91125), and Hiroo Kanamori (California Inst. of Technol., Pasadena, CA 91125)

Seismographs are sufficiently sensitive to detect ground motions induced by atmospheric pressure waves, so seismic networks have the potential to monitor sonic booms over large areas of the United States. They are especially well suited for the analysis of long-range sonic-boom propagation. Ground motion or displacement data provide accurate arrival times and useful estimates of wave amplitude and waveform. The instrumentation is most sensitive to the disturbance produced by the arrival of sonic booms at the measuring station, thus serving as sonic-boom event recorders, but seismographs have also detected seismic waves remotely generated by anomalous coupling of sonic boom into soil. Direct and indirect sonic booms from aircraft operations are routinely detected by the Southern California Seismic Network which consists of 250 seismic stations covering $50000 \mathrm{sq} \mathrm{km}$. Indirect booms from space shuttle landings has been observed at ranges of hundreds of kilometers from the flight path. Data from the network identified "mystery booms" heard in 1992-93 to be long-range indirect sonic booms from offshore operations. Sonic booms generated by space shuttle reentry at Mach 20 and by meteoritic entries into the atmosphere have been detected by seismic networks in the Northwest and Canada.

1pPA3. The prediction of sonic-boom distortion using a scattering center based calculation. Richard Raspet and Henry E. Bass (Dept. of Phys. and Astron., Natl. Ctr. for Phys. Acoust., Univ. of Mississippi, University, MS 38677)

A numerical scattering technique has been developed to calculate the effect of turbulence on sound propagation. This technique resolves the atmosphere into discrete "turbules," calculates the scattered field from each turbule using the Born approximation, then sums all the contributions to form the scattered waveform. The effect of single "turbules" of different scales will be discussed. This technique has been applied to model the atmosphere and the propagation of sonic booms through the planetary boundary layer during the JAPE-2 tests at White Sands. Good agreement was achieved. The limitations and planned improvements will be described. [Work supported by NASAA Langley Research Center.]

1pPA4. Effects of atmospheric stratification on sonic-boom propagation. Robin O. Cleveland (Appl. Res. Labs., P.O. Box 8029, Austin, TX 78713-8029)

Sonic-boom propagation is affected by stratification, geometrical spreading, nonlinear distortion, absorption and dispersion, and turbulence. Stressed in this paper is stratification, in particular its indirect effect on distortion and absorption. The stratification of the density and sound speed leads to refraction and impedance variation, which play a major role in determining the amplitude of the waveform on the ground. Stratification, and associated spreading, can also control the amount of nonlinear distortion a sonic boom suffers. In extreme cases the amount of nonlinear distortion is finite-a phenomenon known as waveform freezing. Analysis shows that for aircraft in the lower $20 \mathrm{~km}$ of the atmosphere waveform freezing does not occur. Through their dependence on temperature, pressure, and humidity, absorption and dispersion are also stratified. A new time domain algorithm, based on a Burgers-type equation, was developed to analyze the effect of the stratification of absorption [J. Acoust. Soc. Am. 96, 3275 (A) (1994)]. The code is used to predict sonic-boom waveforms on the ground. It is demonstrated that sonic-boom shocks are affected not just by local absorption but also by absorption along path for the past $5 \mathrm{~km}$ or so. [Work supported by NASA.]

\section{2:20}

1pPA5. USAF flight test investigation of focused sonic booms. Micah Downing (USAF Armstrong Lab., 2610 Seventh St., Wright-Patterson AFB, OH 45433) and Noel Zamot (USAF TPS, Edwards AFB, CA 93524)

In Aptil 1994, the USAF Armstrong Laboratory in cooperation with USAF'Test Pilot School conducted a measurement study of controlled focus booms generated by supersonic maneuvers. The objective of this study was to collect focus and post-focus booms and to assess the ability of aircrews to control the placement of the focal region during basic maneuvers. Forty-nine flights were performed and included level linear acceleration, level turn, accelerating dives, and climbout/pushover maneuvers. Sonic booms were collected by up to 25 boom event analyzer recorders (BEARs) placed in a $13000-\mathrm{ft}$ linear array. The BEAR units were spaced 500 to $2000 \mathrm{ft}$ apart with the denser spacing at the expected focal region. This spacing was chosen to evaluate the thickness of both the focal and post-focal regions. Of the 49 flights, a focus boom was successfully placed within the array 35 times which demonstrated the ability to place controlled focus booms. This ability of the aircrew can be employed to avoid collateral damage to noise sensitive receptors. Along with capturing focus $U$ waves, complex $N-U$ signatures were recorded at distances away from the foci. Turbulent conditions had a defocusing effect, resulting in smaller maximum overpressures.

\section{2:40}

1pPA6. The theoretical and computational basis of focused sonic booms. Kenneth J. Plotkin (Wyle Labs., 2001 Jefferson Davis Hwy., Suite 701, Arlington, VA 22202)

For the past 20 years sonic-boom signatures in focus "superboom" regions have been computed using a method based on a scaling law by Guiraud [J. Mech. 4, 215-267 (1965)] and a numeric solution by Gill [Ph.D. thesis, Cornell University (1974)]. The method recognizes that the smooth caustic case treated by Guiraud and Gill is by far the most common focusing situation, and that smooth caustics caused by aircraft accelerations and turns and by atmospheric gradients are topologically similar. Gill's numeric result for a shock may thus be treated as a canonical result, and scaled to arbitrary situations by Guiraud's similitude. The process has been 